\title{
Construction Mode and Strategy Research on Micro Idyllic Complex in Wuxing, Huzhou
}

\author{
Jiayan $\mathrm{Fu}^{1,}$, , Zhu Wang, b, and Zhongqi $\mathrm{Yu}^{3, \mathrm{c}}$ \\ ${ }^{1}$ Room 214, Yueya Building, 866 Yuhangtang Road, Zhejiang University, Hangzhou, China \\ ${ }^{2}$ Room 214, Yueya Building, 866 Yuhangtang Road, Zhejiang University, Hangzhou, China \\ ${ }^{3}$ Room 402, No. 1230, Siping road, Yangpu district, Tongji University, Shanghai, China \\ afujiayan513@qq.com, b13325716901@163.com, czhongqi5081@163.com
}

Keywords: Wuxing, Huzhou; Idyllic Complex; Micro; Rural Construction; Family Farm

Abstract. In 2017, for the first time, the "Idyllic Complex" is included in the Document No.1 of the Central Government. This paper demonstrates the core construction mode and strategy of "Idyllic Complex" through analysis of its five features. The "Idyllic Complex" needs to follow the "regional gene". According to the widespread characteristics such as broken geography pattern, peasant economy history, family society structure, culture tradition diversity and traffic convenience in the southern Yangtze River, the author raises the concept "Micro Idyllic Complex" and detailed introduces a typical example "Puxin Family Farm" project.

\section{Introduction}

At present, with the third consumption structure upgrade, the citizens are no longer satisfied with consumption being restricted in "Reinforced Concrete Forest". Thus, the upgrade is driving the development of rural industry. Different from relatives visiting, government plans such as farm stay, beautiful village construction, characteristic town construction and modern manor actually offer jobs to the countryside. "Idyllic Complex" is an innovative approach to rural construction focus on agriculture reformation. [1]

\section{Method}

This paper divides "Idyllic Complex" into 5 words in Chinese: "Tian", "Yuan", "Zong”, "He", "Ti". Through resolution and combination of 5 words above, the author analyze elements and organization pattern of "Idyllic Complex" in depth (Fig. 1) and demonstrate core content on its construction mode and strategy method.

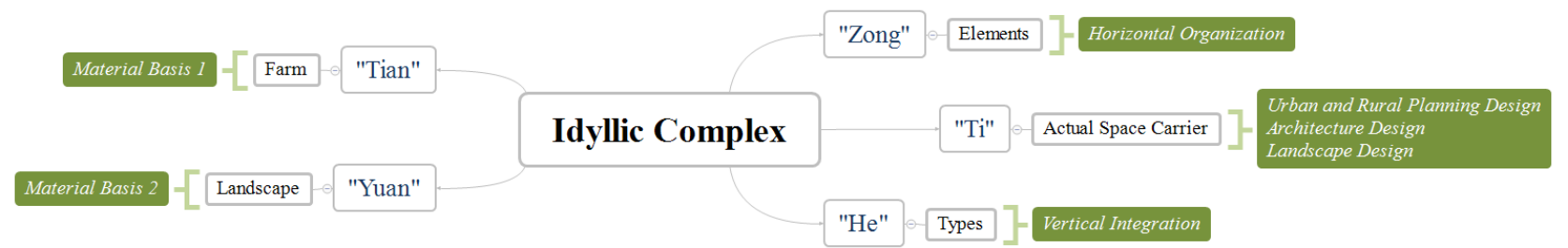

Fig. 1: Resolution and Combination of Idyllic Complex

"Tian": Agriculture, material basis 1. "Tian" is the first material basis of Idyllic Complex. Different from characteristic town which regard manufacture and tourism as main industry, primary industry "Agriculture" is the core industry for Idyllic Complex. Other industries in rural area need to be implemented on "agriculture". Meanwhile, farmer cooperatives or family farm need to be the main carrier to make sure farmers' participation and benefit.

"Yuan": Landscape, material basis 2. "Yuan" is the second material basis of Idyllic Complex. As the main component of the third industry "service" in rural area, tourism landscape resource is indispensable. Landscape resource can cause activities of aesthetic appreciation and tourist behavior, and progresses to more environmental, social and economic benefits. According to the degree of 
integration, tourism agriculture, leisure agriculture and creativity agriculture are the good representatives of low, medium and high level.

"Zong": Horizontal organization of elements. Idyllic Complexes have various types and scale, but they are made up of the same key elements. "Zong" reveals the horizontal organizational mode of these elements: Economic element, geography element, social element, cultural element, space element and so on [2]. With internal diversification, they also affect each other, even minor changes will cause the change of other elements as well as overall system. The construction of Idyllic complex is just similar to weaving process, the element wire is independent but related to others in the same time, under the guidance of heddle rod, element wires move together, and finally weave out the fabric: Idyllic Complex.

"He": Vertical integration of elements. Every element of "Idyllic Complex" such as economy, geography, society, culture and space can be divided into various types. "He" reveals the internal integration of element types. Along with the process of urban-rural integration, more types appear in people's vision and attract public attention. Take the economic element type for example, the requirement of rural industry development in No. 1 document is keep growing for the past years. From 2004 to 2014, it's mainly about the primary industry, adjust the agricultural structure, increase agricultural investment and strengthen agricultural support protection. In 2015, it proposed that the rural areas also need development with integration from primary industry to tertiary industry. In 2017, the No. 1 document raised "Idyllic Complex", which is actually the updated version of "rural industry integration". In addition, rural people are no longer limited to ordinary peasant. New farmers, investors, scholars and consumers enrich the type of the people in rural area. When these identities are combined, new social element types such as family farm, farmer cooperative and third-party platform appear, once again enrich the types of social element.

"Ti": space carrier in urban planning and architecture. Finally, the material basis, element modular, type structure need to be organized in urban planning, and be expressed through buildings and space. The idyllic complex is finally achieved when the idyllic space is formed. The public is no longer satisfied with the single material need, but upgrade to a nutritious and experienced dual needs of material and spirit. Therefore, the rural areas are no longer only the output place of agricultural production, but also the public tourists' destination, the function of rural buildings are not limited to farmers' production and living, but extended to dining, entertainment, conference and so on.

\section{Discussion}

"Puxin Family Farm" is near the mountain and by the river. It is a micro scale complex prototype with all necessary elements, like ecological element, productive element and rural life element. Regarding to space, "Puxin Family Farm" [3] already has kitchens, dining rooms and hotel rooms which meet service needs, as well as lecture hall, reception center, creativity agriculture, idyllic walking system which represent farming-studying culture.

Farming-reading lecture hall. It is only in the dynamic development of variation and sublimation that the farming-reading culture can achieve inheritance. Thus, it must be activated in actual space carrier. Before renovation, it was an abandoned sheepfold with dilapidated façade for stacking tools (Fig. 2). The author keeps the original structure and implant the lecture function as education and meditation space. Entrance renovation is to create the sense of solemnity. Roof restoration and bamboo façade addition with ringing sound are to revitalize architecture (Fig. 3). Two brick walls are set inside each with 99 holes represent hope from the farmer to the farm. Almost all the furniture is made of wood, which presents a natural taste and expresses a spiritual revival of "face to land and return to life". [4] 

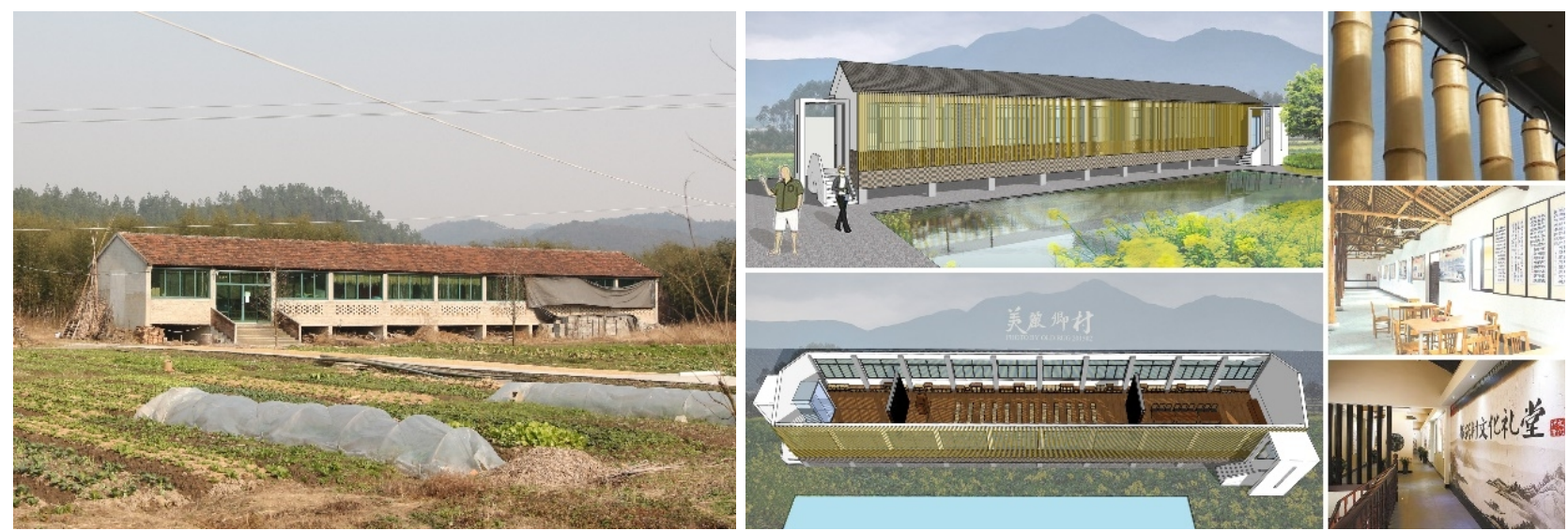

Fig. 2 Farming-Studying Lecture Hall (Before) Fig. 3 Farming-Studying Lecture Hall (After)

"Puxin" Inns. Original dormitory in "Puxin Family Farm" is in poor condition (Fig. 4) which can only accommodate within 6 family members as well as 1-2 staff members, it's not enough for tourist accommodation. [5] Although "Puxin Family Farm" and "Lion Hill Hotel" have established cooperation relationship between agriculture experience and accommodation, most consumers still prefer 24 hours stay in farm. Therefore, "Puxin Family Farm" has renovation and expansion demands. The original structure is preserved, the 1-storey master bedrooms is expended to a 2-storey mixture with master bedrooms and guest bedrooms (Fig. 5). The façade is improved by simple and concise grille and pergola. As agriculture land is valuable, permeable concrete is used to harden the dormitory frontcourt road. Low walls are used to highlight the boundary between yard and road without blocking sight. Create leisure and gathering places while ensuring privacy.

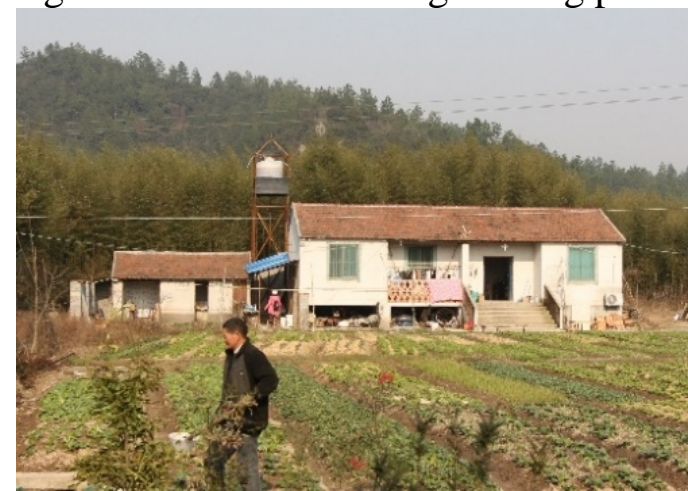

Fig. 4 "Puxin Inns" (Before)

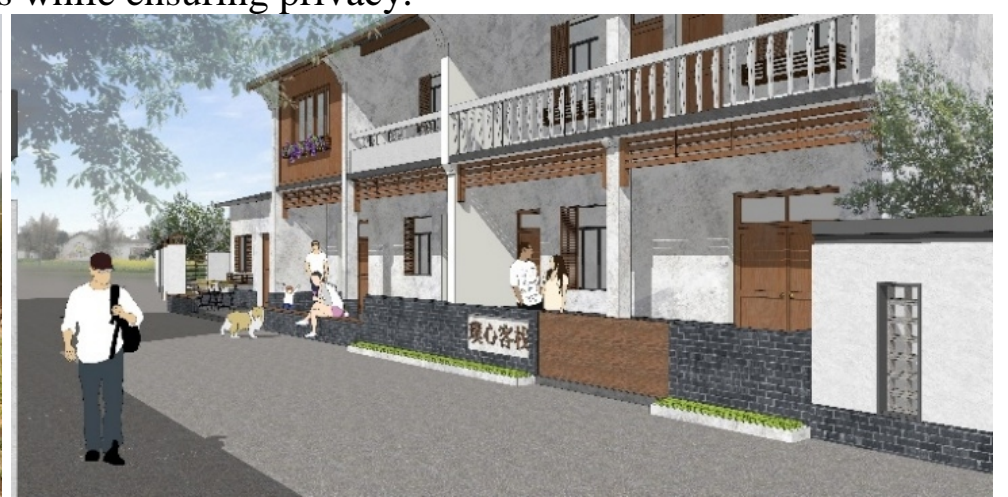

Fig. 5 "Puxin Inns" (After)

Grain-sunning Ground. The site needs to be adjusted and used dynamically. During busy farming period, there is a shortage of site but during free farming period, there is a vacancy of site. This unbalanced phenomenon above is been there alternatively for a long time. The basketball rack is installed. When it is busy farming time, the site will be used as grain-sunning ground. When it is free farming time, the site will be used as playground or parking lot (Fig. 6).

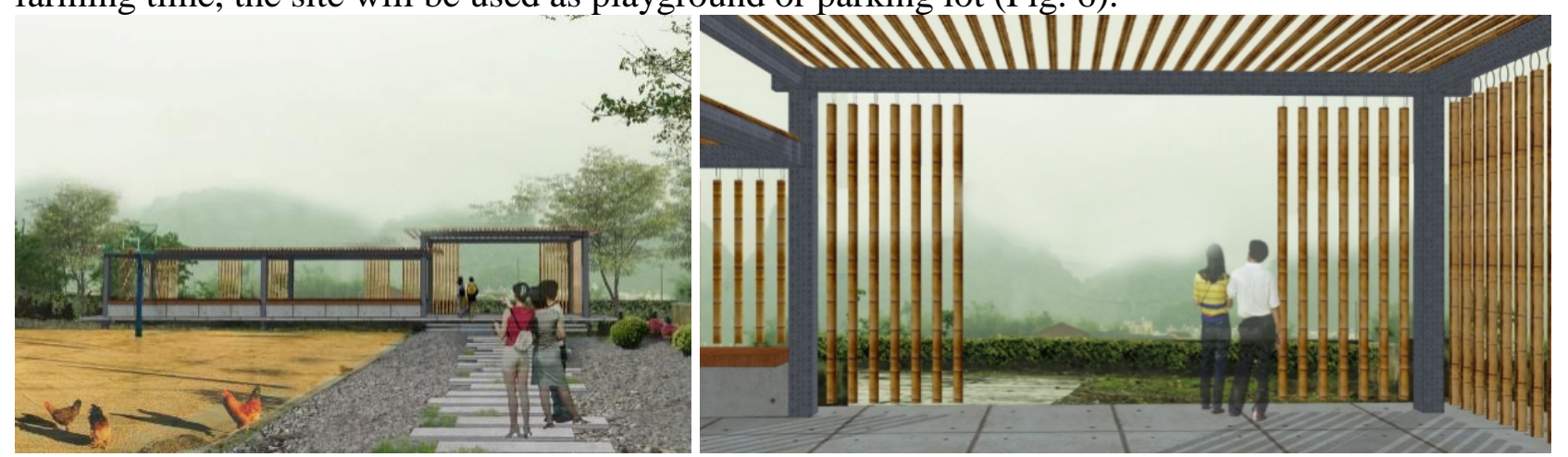

Fig. 6 Grain-sunning Ground, Parking Lot (After)

Art field. The original farm only have primary industry, therefore, we select proper core position of the farm, reorganize the cultivated land, in the same time, added art field landscape and experience 
activity, thus increase the agricultural value. Urban children can experience the farming-studying culture, not only expand their knowledge, enjoy fun, but also educate them by facing the harvest of hard working. After being polished by creative agricultural brand, the "not perfect but real" and "natural farming" idea have become famous around the Huzhou agricultural market (Fig. 7).
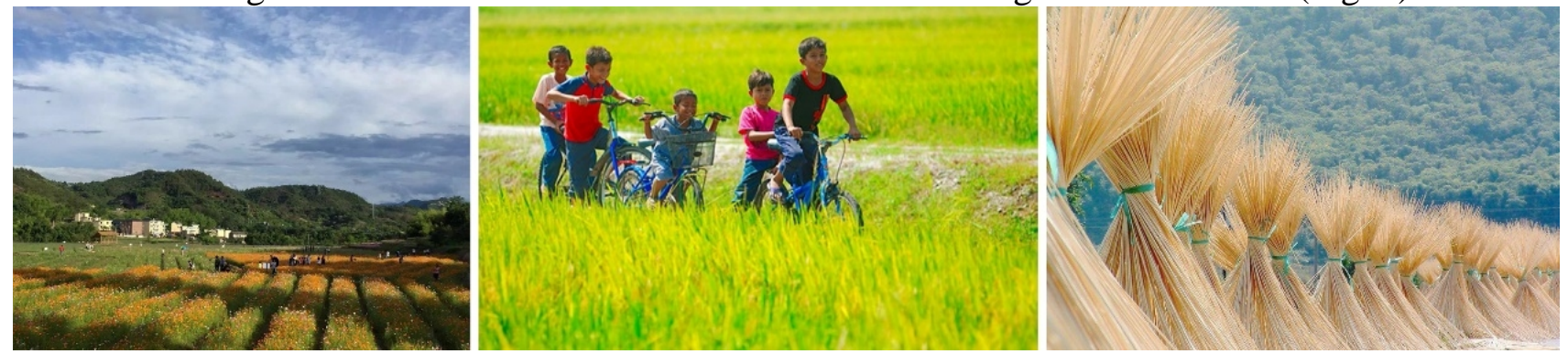

Fig. 7 Art Field Illustration

In addition, we sorted out streamline of different level inside the farm, designed landscape nodes, established slow flow line for leisure activities like walking and riding. In order to achieve organic renovation in this farm, the reception, restaurant and kitchen are included in the $2^{\text {nd }}$ phase, thus the value of farmland is activated and overall environment is improved.

\section{Conclusion}

The thinking origin of "Idyllic Complex" is exploration of sustainable development path in Chinese rural area. In the important period of agriculture development transformation in China, although "Idyllic Complex" is officially put forward by central government until 2017, there are a lot of practice explorations in various regions. From these practice projects, we should summarize the success and fail experience carefully. The author takes "Micro Idyllic Complex" as a breakthrough of new rural construction, and raises a point that reform agriculture structure and pattern to promote agriculture modernization.

\section{References}

[1] Xuefeng He, Agricultural Modernization Should First be the Modernization of Small Farmers, China Rural Science \& Technology, 2015(06): 21.

[2] Xiangzhi Kong, Constructing Idyllic Complex with Farmers as the Main Body. Liaoning Daily, 2017-06-13(006).

[3] Jiayan Fu, Zhu Wang, Zhenlan Qian, Jiaojiao Sun, Strategies and Practices on "Primary Unit Complex" of Accurate Rural Construction in Jiangnan Region: Take "Puxin Family Farm" In Huzhou Zhejiang as an Example, Urbanism and Architecture. 2017, (10), p: 14-17.

[4] Yong He, Weiwei Sun, Jiaojiao Sun, Reflections and Teaching Practices of Architectural Education towards the Ground and Everyday Lives, Architectural Journal, 2017(01), p: 54-57.

[5] Hui Li, Research on the Innovation of Tourism Industry from the Perspective of Global Tourism: Take Idyllic Complex as Example, Economic and Geographical Professional Committee, the Geographical Society of China, 2017: 1. 